\title{
An Elective Mathematics Readiness Initiative for STEM Students
}

\section{Dr. Janet Callahan, Boise State University}

Janet Callahan is the Founding Associate Dean for the College of Engineering at Boise State University and a Professor in the Materials Science and Engineering Department. Dr. Callahan received her Ph.D. in Materials Science, her M.S. in Metallurgy and her B.S. in Chemical Engineering from the University of Connecticut. Her educational research interests include freshmen engineering programs, math success, K-12 STEM curriculum and accreditation, and retention and recruitment of STEM majors.

\section{Ms. Judith A. Garzolini, Boise State University}

Judith (Jude) Garzolini is the National Science Foundation (NSF) Grant Project Manager for the Idaho STEP grant at Boise State University. She is responsible for managing the \$1 Million grant to plan and implement activities focused on increasing the throughput of graduates in Science, Engineering, and Mathematics. During her over 23-year career in industry she worked for Hewlett-Packard Company where she contributed as both an $\mathrm{R} \& \mathrm{D}$ project manager and program manager in the disk drive and printing supplies businesses.

Jude received a B.S. in Chemical Engineering from Wayne State University and a Master of Business Administration from the University of California, Davis. She was the 2007 national president of the Society of Women Engineers. Her educational research interests include recruitment and retention of women and minorities in STEM related fields, with a special focus on engineering. 


\title{
An Elective Mathematics Readiness Initiative for STEM Students
}

\begin{abstract}
This paper reports on the longitudinal results of an online elective mathematics readiness initiative for undergraduate students majoring in science, technology, engineering and mathematics (STEM) at Boise State University. This initiative was put in place in summer of 2010, and over five years has involved 766 total users. It utilized an online commercial system for mathematics learning, focusing mainly on the content associated with preparation for Calculus and preparation for Pre-Calculus. Funding to enable the initiative was derived from the National Science Foundation under a Science, Talent Expansion Program grant. The licenses were issued to students who elected to participate and who then had 77 days of learning available to them. Incentives for participation were provided, including bookstore awards (\$100 to \$200) if a certain threshold for learning was achieved by the student. These thresholds included from 15 to 20 hours of learning, to 95\% completion of course content. This paper reports on the methodology for recruiting students to the initiative, on the longitudinal results of students in subsequent mathematics as a function of effort put into their online mathematic review, on adjustments made to the initiative over time as we learned more about student behavior and motivation, and on student retention of this subset of students in STEM majors.
\end{abstract}




\section{Introduction:}

As part of a multifaceted, grant-funded effort focused on increasing undergraduate STEM retention in order to increase science, technology, engineering and mathematics (STEM) graduation rates at Boise State University, ${ }^{1}$ funds were used to purchase online mathematics tutorial program user licenses on a user-elective basis for STEM students. The basis for doing so was grounded in the university and engineering retention literature which underscores the importance of doing well in terms of academic performance (GPA) in a students' first semester/year (e.g. Budny, et al). ${ }^{2}$ This project aimed to help students with academic performance by providing a mechanism for students to efficiently review mathematics prior to the start of the academic year.

The tutorial program employed was ALEKS ${ }^{\mathrm{TM}}$ (Assessment and Learning in Knowledge Spaces), a web-based, artificially intelligent assessment and learning system that uses adaptive questioning to determine what a student knows and what they do not yet know in a course.,4 The motivation for using ALEKS ${ }^{\mathrm{TM}}$ arose from prior work and from the work of others, showing significant impact when used in conjunction with Calculus classes ${ }^{5}$ and when used for assistance in mathematics placement. ${ }^{6}$ No other tutorial systems were explored.

This interactive online mathematics tutorial has been used at Boise State University since 2006 in order to affect the success of students enrolled in undergraduate programs. It has been used, for example, as a supplement to an engineering course ${ }^{7}$ and also to help assess student readiness for college level coursework. ${ }^{8,9}$ It is also currently used by the Math Learning Center for all coursework below Calculus I. This paper reports on an additional use of this tutorial program, ALEKS $^{\mathrm{TM}}$, in effect between 2010 and 2015 at this university. This has been to provide free licenses to STEM students, on an elective basis, who present at the university during first-year or transfer orientation programs, and to returning students who have received course grades lower than a $\mathrm{C}$ in college level mathematics coursework including intermediate and college algebra, precalculus, trigonometry and calculus I.

This paper is not presented as a formal study; it lacks a control group since it relies on elective participation. Rather, the focus of this paper is on how this effort recruited participants, how some of those elective participants performed in subsequent college mathematics classes relative to other STEM majors, and how the project was managed, including lessons learned over the course of the project.

\section{Procedures:}

\section{$\underline{\text { Recruitment of Elective Participants }}$}

We currently have two chief strategies for recruiting students. The first of these takes place in summer orientation events for first-time and transfer students. The process starts with an email sent starting in April to prospective students who have been admitted to the university and who have registered for a summer orientation session. Very few students accept this first offer for a free license, but this is the first of several recruitment emails. During summer orientation, STEM 
students are grouped together as a cohort, and hear again about ALEKS ${ }^{\mathrm{TM}}$ in several different ways. This includes hearing about it during the opening greeting to STEM students given by a STEM academic leader, usually a Dean, in a slide. It also includes having a poster present in the room, e.g. see Figure 1; through the wearing of "Ask me about ALEKS TM" buttons worn by peer advisors during orientation and by having fliers available on a table during preregistration. Following summer orientation, approximately one week later, a second email is sent reminding students of the opportunity; this email garners the most responses with many students electing to receive licenses one to two weeks following STEM summer orientation. In addition, advisors who interact with students also receive fliers and email information so that they are conversant with the opportunity. We have found that transfer students are quite receptive to the concept

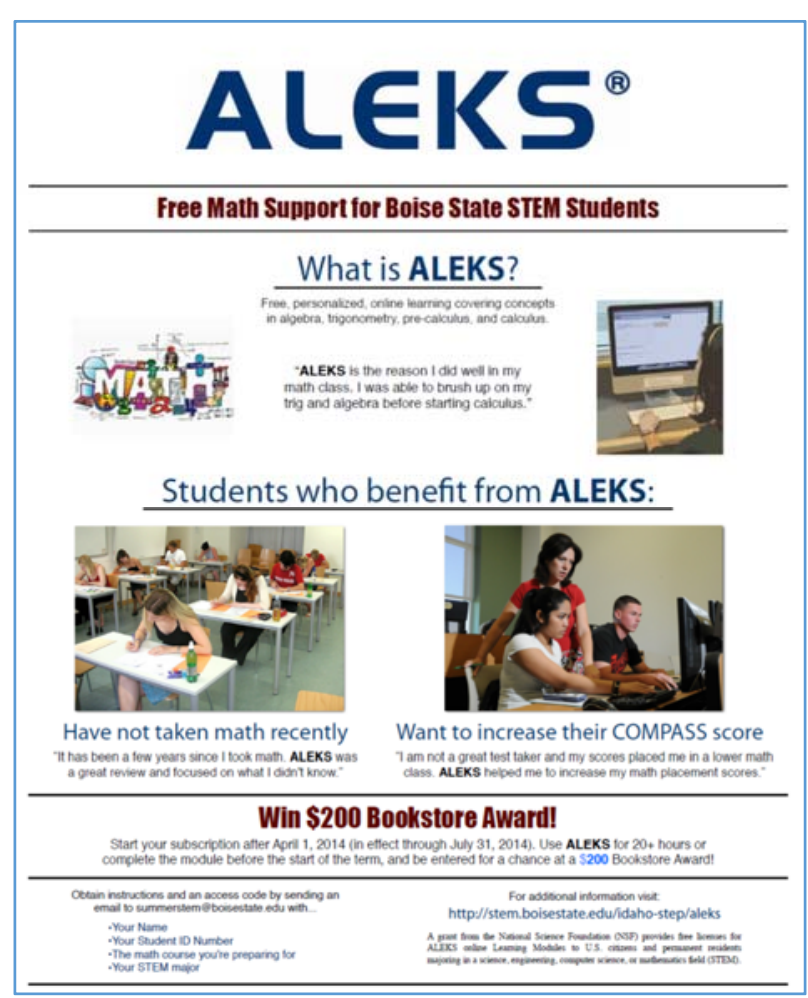

Figure 1: ALEKS recruitment poster during transfer orientation because many have just taken a COMPASS math placement test and are disappointed with their placement results; ALEKS ${ }^{\mathrm{TM}}$, through this program, provides a formal review pathway so as to prepare for a second placement test. Advisors to STEM students also emphasized participation; these advisors were present at all the transfer and first-time student orientation events. Information was also posted on departmentally maintained Blackboard sites. Fliers and posters were routinely used, particularly during orientation. Recruitment of participants was additionally conducted using the Louis Stokes Alliance for Minority Participation (LSAMP) program at Boise State, through personal interaction, email and the LSAMP website.

The second major recruitment strategy is focused on continuing students and occurs following end of spring and fall semester, after running a "DFW" report (students who receive a grade of D, F or W) on STEM students in Intermediate Algebra (IntAlg), College Algebra (ColAlg), Trigonometry (Trig) or Calculus I (CalcI). These are invited to receive an ALEKS license over winter or summer break. One final and recent method of recruitment has been more directive, being linked as a requirement for incoming students who qualified for a NSF S-STEM scholarship. Nine students were recruited via this pathway.

All students, regardless of recruitment strategy are incentivized to achieve either 15 or 20 hours of online learning or to score higher than 95\% in terms of completion of their online course through the promise of a bookstore award (limited for use in purchasing text books). For the first four years, this was set at a level of $\$ 100$; for the fifth year it was increased to \$200. Twice a year, student progress was reviewed and bookstore awards made. 


\section{$\underline{\text { Deadlines }}$}

Although the online learning strategy was self-paced, there were two hard deadlines for students. These included the license expiration date (it is in effect for 77 days after it is activated), and the deadline for completing goals for securing the bookstore award. Students were made aware of the latter deadline through multiple emails sent by the project coordinator.

\section{Results and Discussion}

\section{LICENSES AND AWARDS ISSUED}

In total, 834 licenses were issued between May, 2010 and January, 2015, see Table 1. In terms of licenses issued, $34.1 \%$ of them were to female participants and $14.7 \%$ were to underrepresented minority students (URM: Alaska native/Native American/Black/Hispanic/Hawaiian or Pacific Islander). $45.6 \%$ were to first-time, full-time students; $16.5 \%$ to transfer students and $35.4 \%$ to returning students.

\begin{tabular}{|c|c|c|c|c|c|c|c|}
\hline Table 1: Details on Participants who elected to use ALEKS \\
\hline Category & N & Female & URM & Transfers & FTFT & Returning & 2nd degree \\
\hline $\begin{array}{c}\text { Total users who } \\
\text { requested ALEKS }\end{array}$ & 834 & 284 & 123 & 138 & 350 & 295 & 51 \\
\hline $\begin{array}{c}\text { awardees } \\
\text { STEM enrollment fall } \\
2013\end{array}$ & 164 & 63 & 22 & 46 & 66 & 36 & 16 \\
\hline
\end{tabular}

In terms of the demographics of awards issued, 38\% of awards went to female students, a level which significantly exceeded the fall, 2013 female STEM enrollment figure (26.5\%). In addition, $13.4 \%$ of awards went to underrepresented minority students. These also significantly exceeded the fall, 2013 URM STEM enrollment figures which reflect a student body consisting of 9.2\% URM. When awards were evaluated in terms of student enrollment category we found that $40 \%$ of awards went to first-time, full-time students, $28 \%$ went to transfer students, $22 \%$ to returning students and $10 \%$ to second degree seeking students.

When the retention of FTFT students who received awards was examined, we found that $71.4 \%$ of awardees were retained in STEM one year later, and 81.6\% were retained here in any major. This favorably compares with STEM FTFT retention figures that have been rising as a result of focused retention efforts from 58.2\% (2010 and 2011 average) to 63.8\% in 2013-14, and with the STEM FTFT cohort retention in any major of 75.1\% (2013-2014). Boise State University FTFT figures (all majors) in the same four years have also been rising, from 70.3\% (2010 and 2011 average) to the most recent figure of $74.7 \%$ (2013 cohort).

Of the 834 licenses issued, Table 2, unique recipients received 766 of them. A total of 59 students received a second license, 7 received a third license and 2 a fourth, across multiple semesters. Of these, 22 students received one

\begin{tabular}{|c|c|c|c|}
\hline \multicolumn{4}{|c|}{ Table 2: Award History 2010 - 2014} \\
\hline Years & $\begin{array}{c}\text { Licenses } \\
\text { Issued }\end{array}$ & Awardees & $\begin{array}{c}\text { Award } \\
\text { Amount }\end{array}$ \\
\hline 2010 & 86 & 26 & $\$ 100$ \\
\hline 2011 & 195 & 36 & $\$ 100$ \\
\hline 2012 & 200 & 31 & $\$ 100$ \\
\hline 2013 & 176 & 26 & $\$ 100$ \\
\hline 2014 & 177 & 45 & $\$ 200$ \\
\hline Total & 834 & 164 & $\$ 20,900$ \\
\hline
\end{tabular}


award and four received a second award for completing another course module and satisfying the criteria. Thus, receiving an award was motivational to students to elect to continue their independent mathematics learning. Students who received multiple licenses were at lower mathematics levels.

A total of 164 students received bookstore awards as a result of having used ALEKS ${ }^{\mathrm{TM}}$ for either 15 or 20 hours or scored higher than $95 \%$ in terms of completion of their online course, see Table 2. Thus, $19.7 \%$ of the participants qualified to receive an award. The increase of the magnitude of the bookstore award from $\$ 100$ to $\$ 200$ markedly increased the number of awardees although it did not affect the number of licenses issued; note that 5 of the 45 awardees came from spring, 2014 while the award was still $\$ 100$.

\begin{tabular}{|c|c|c|c|c|}
\hline Table 3: ALEKS Awardee Summary \\
\hline Course & $\begin{array}{c}\text { Bookstore } \\
\text { Awardees }\end{array}$ & $\begin{array}{c}\text { Average } \\
\text { University } \\
\text { grade }\end{array}$ & $\begin{array}{c}\text { Average } \\
\text { ALEKS } \\
\text { Mastery }\end{array}$ & $\begin{array}{c}\text { Average } \\
\text { ALEKS } \\
\text { Hours }\end{array}$ \\
\hline Elem Alg & 5 & 3.54 & 52.0 & 27.5 \\
\hline Intermed Alg & 17 & 3.57 & 69.1 & 31.4 \\
\hline Coll Alg & 14 & 3.41 & 77.9 & 32.8 \\
\hline Trig & 16 & 3.23 & 89.9 & 29.5 \\
\hline PreCalc & 20 & 2.62 & 78.1 & 39.6 \\
\hline Calc I & 71 & 2.85 & 90.5 & 30.5 \\
\hline Calc II & 4 & 3.68 & 97.8 & 19.7 \\
\hline Discrete Math & 7 & 2.10 & 88.1 & 48.9 \\
\hline Calc III/DiffQ & 2 & 4.00 & 98.0 & 5.6 \\
\hline
\end{tabular}

The distribution of awardees in terms of level of their subsequent university math course is shown in Table 3, as well as average data showing average grade earned in their subsequent university math course, average mastery within the course they were enrolled in and hours spent learning. The predominant course taken by awardees following their participation was Calc I, accounting for $46 \%$ of the awards. Another $46 \%$ of the awards were given to students who enrolled in various courses at levels below Calc I, see Table 3 and Figure 2. A small minority of students took other courses, including 4.5\% of awardees taking Discrete Math and two students taking Calc III or Differential Equations. A small number of students $(\mathrm{N}<10)$ who qualified for an award did not enroll in a mathematics course or else did not enroll at the university.

For Calculus I students, hours spent reviewing online, or \% mastery of material do not correlate with high grade in the subsequent math course. This is surprising and may be due to a variety of factors, one of which could be that students could have simply been motivated to achieve the minimum hours to qualify for a bookstore award and may not have been honestly learning, but rather receiving assistance (electronic or otherwise) to answer questions correctly.

Of the 164 students who received awards, performance in subsequent math course was markedly different from that of 6,890 other STEM students taking that math class between 2010 and 2015, see Table 4. At all mathematics course levels, grades were higher, with levels of grade point average increase ranging from 0.77 to 1.23 . It is expected that students with initiative to elect to participate in a mathematics review would

\begin{tabular}{|c|c|c|c|}
\hline Table 4: STEM - ALEKS Math Performance \\
\hline Course & $\begin{array}{c}\text { STEM Average } \\
\text { University grade }\end{array}$ & $\begin{array}{c}\text { Awardee } \\
\text { Average grade }\end{array}$ & Increase \\
\hline Intermed Alg & 2.61 & 3.57 & 0.96 \\
\hline Coll Alg & 2.18 & 3.41 & 1.23 \\
\hline Trig & 2.27 & 3.23 & 0.96 \\
\hline PreCalc & 1.85 & 2.62 & 0.77 \\
\hline Calc I & 2.08 & 2.85 & 0.77 \\
\hline Total Students & 6890 & 138 & \\
\hline
\end{tabular}


outperform the rest of the population; this is provided as a reference point only relative to the STEM student performance as seen by grade point average at the various course levels.

In the most recent award year, nine students were required to use ALEKS ${ }^{\mathrm{TM}}$ to achieve the award goal as a condition for receiving a scholarship. All nine students received awards; of these, six were female and two were underrepresented minority students. Eight of the nine students passed their math courses; six with grades of $\mathrm{A}$.

\section{PRoject Management: Lessons LEARNED}

\section{Program Promotion}

In the first year of the program, we promoted the mathematics readiness initiative by sending announcements to STEM advisors and public announcements to students attending STEM summer orientation to make them aware of the availability of the opportunity. We quickly learned that students were overwhelmed with the wealth of information that flowed to them regarding the myriad available programs. The lesson was that we needed to make the student aware of ALEKS ${ }^{\mathrm{TM}}$ before they came to orientation, during orientation using a combination of presentations, flyers, bookmarks on orientation tables, etc. and after they returned home from the orientation. Frequently we would hear students say they wanted to participate in the initiative and promptly forgot about the tool once they left campus and returned home. We learned to keep repeating the message.

We changed our messaging to be about refreshing math skills and using it as a study aid to place in the math course they desired. This was necessary in order to differentiate it from another initiative involving ALEKS ${ }^{\mathrm{TM}}$ and math placement, which required all students electing to take certain classes to take an online ALEKS ${ }^{\mathrm{TM}}$ assessment and score at a specified level of assessment by the 10th day of class. We found that many students thought the learning module was for assessment only - not as a study aid to support their success. In June of 2012, the mathematics department dropped the requirement for ALEKS ${ }^{\mathrm{TM}}$ assessment. This allowed us to more clearly promote the mathematics readiness initiative.

In winter 2012, in an effort to proactively take measures to improve retention by supporting students who were struggling to succeed, (e.g. see recommendations of Whalen, et al. $)^{10}$ we began recruiting students who did not pass their math in fall by developing a list of all students who performed at the $\mathrm{D}, \mathrm{W}$, or F level in algebra, trigonometry, and calculus and sending out promotions to them encouraging them in their STEM careers while also providing an opportunity for reflection about how to make their next semester go better. As a part of this communication, we recommended the use of the free ALEKS ${ }^{\mathrm{TM}}$ online learning module.

We used student testimonials to help promote the program, obtaining permission from students who qualified for the bookstore award to use to use a photo that they submitted in combination with "words of wisdom" for future students considering using ALEKSTM. We then used these pictures and phrases to develop our posters and website recruitment material, see inset figures.

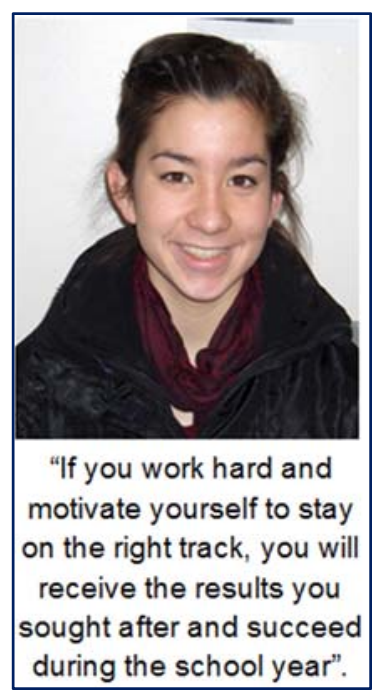




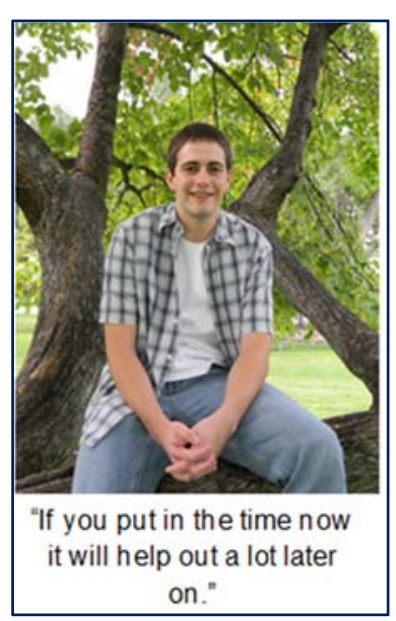

Finally, we created full size posters in 2013 to be used in the Math Learning Center, the rooms used for STEM summer and transfer orientation, and the hallway outside the STEM community area to ensure students were made aware of the tool.

\section{License Distribution}

Over time, we developed a methodology for distributing licenses. At first, we issued licenses during summer orientation by handing out tickets with the license registration that had been purchased. This method was quickly abandoned as many students never even logged into the system to register. We then moved to a system where students had to take an active step by expressing interest through sending an email request, often through a reply to an informational email, that included

their name, student ID number, major and the course of interest (Prep for IntAlg, Prep for PreCalc, Prep for Calc). This method increased the number of students who then went on to actively learn and review math online.

Our initial distribution of ALEKS ${ }^{\mathrm{TM}}$ codes required a student request and a signed consent to use their data. In June 2011 we moved to an online system which required students to send an email to a dedicated email address which included information about the student's email address, major, student ID and the mathematics course they for which they wanted to prepare. In return, they would receive a 20 character access code, and written instructions about how to access the online course.

The risk with this method was that students may not activate the code thus wasting the grant investment of $\$ 40 /$ code. However, the advantages included:

- Allowing a single ALEKS ${ }^{\mathrm{TM}}$ portal for the university, which allowed the math department to access progress records for all students in 1 location.

- Allowing easier tracking of grant licensee performance by listing all students who had these licenses. Also, it allowed us to contact the user to remind them to use the subscription, to complete their use to qualify for a bookstore award, or inquire if they were having any problems with the application. In addition, we acquired information which gave us easier analysis of the student user's performance in future math courses.

Over the 4 years of the grant we have changed the Learning Module offerings. Initially we offered only 2 courses which supported the entering mathematics requirement for pre-calculus and calculus which required students to score at a specified level on the ALEKS ${ }^{\mathrm{TM}}$ Learning Module to confirm enrollment in these courses within the first ten days of the semester. We were able to promote the courses as a good way to build the necessary skills and receive a bookstore funding award. Over time we adjusted the number of Learning Modules offered. Our last adjustment was made from two specific inputs:

First, we identified that $70 \%$ of our entering 2010 STEM student cohort had math readiness levels in the intermediate algebra and pre-calculus areas. Correspondingly students at these readiness levels were retained at an average STEM retention level of 53\%. The large number of students and the low retention rate made the move to include a third module, algebra a wise 
choice in increasing our support to these students. Second, the director of the Math Learning Center has had good success using ALEKS ${ }^{\mathrm{TM}}$ as a teaching tool. He strongly supported moving to 3 course modules, to help to address the preparedness of students who were not yet ready to enter calculus. As a result we began offering 3 Learning Module levels in fall of 2012.

\section{Summary}

In summary, an elective mathematics readiness initiative was funded for five years. A total of 766 unique participants received 832 licenses. Bookstore awards were made to approximately $20 \%$ of the participants. A higher award level of \$200 as compared with \$100 resulted in substantially more license recipients completing the award requirements (either 15 or 20 hours of online learning or scoring higher than $95 \%$ in terms of course completion). The female demographics of the awardee population significantly exceeded the female STEM demographics (38\% and 27\%, respectively). The URM demographics of the awardee population also exceeded the STEM demographics (13.4\% and 9.2\%, respectively). Awardees have a significantly higher first-time, full-time (FTFT) retention rate in STEM majors as compared with all FTFT STEM students (71.4\% and 63.8\%, respectively). While this report offers results of great interest higher female and URM award levels, for one, this report also contains a significant limitation: the participant population was elective. Because of this, formal conclusions about the efficacy of this readiness initiative in terms of increasing student outcomes such as improved retention are prevented.

In terms of project management, an outline of effective strategies used for participant recruitment and license distribution was presented in order to preserve the lessons we learned while administering this program. Others who are considering a similar initiative are encouraged to find a way to link personal investment with participation, in order to increase the relative number of students investing significant quantities of time. This could be done by partially subsidizing the cost of a license, or by reimbursing the cost of the license as part of the bookstore award. At the time of this writing, we do not plan to continue this program here, for lack of funding.

\section{Acknowledgments}

This material is based upon work supported by the National Science Foundation under Grant Nos. DUE-0856815.Any opinions, findings, and conclusions or recommendations expressed in this material are those of the author(s) and do not necessarily reflect the views of the National Science Foundation.

\section{References}

1. J. Callahan, J. Garzolini, G. Hunt, J. Guarino, D. Bullock, S. Shadle, C. Schrader, “The Science Talent Expansion Program: Freshman Orientation for STEM Majors,” American Society for Engineering Education Annual Conference \& Expo, Vancouver, BC, 2011 AC 2011-2500.

2. D. Budny, W. LeBold, G. Bjedov, “Assessment of the Impact of Freshman Engineering Courses,” Journal of Engineering Education, 1998, 405-411. 
3. ALEKS corporation website, www.aleks.com, 3 March, 2015.

4. J.C. Falmagne, M. Koppen, M. Villano, J-P. Doignon and L. Johanessen, "Introduction to Knowledge Spaces: How to Build, Test and Search Them,” Psychological Review, 1990, 97, 201-224.

5. J.P. Carpenter and R.E. Hanna, "Predicting Student Success in Calculus," Proceedings of the 2007 American Society for Engineering Education Conference, AC 2007-58

6. A. Ahlgren and M. Harper, “Assessment and Placement through Calculus I at the University of Illinois,” Notices of the American Mathematical Society 58 (10) 1460-61, 2011. http://www.ams.org/notices/201110/rtx111001460p.pdf

7. J.M. Hampikian, J.F. Gardner, A.J. Moll, P.A. Pyke and C.A. Schrader, "Integrated Pre-Freshman Engineering and PreCalculus Mathematics," CD-Proceedings of the 2006 American Society for Engineering Education Annual Conference \& Exposition, Chicago IL, 2006-933, pp. 1-11 (2006).

8. D. Bullock, J. Callahan, Y. Ban, A. Ahlgren, C. Schrader, "The Implementation of an Online Mathematics Placement Exam and its Effects on Student Success in Precalculus and Calculus," American Society for Engineering Education Annual Conference \& Expo, Austin, TX AC 2009-1783 (2009).

9. S.Y. Chyung, J. Callahan, D. Bullock, K. Bridges, J. Guild, C. Schrader, “Improving Students’ Learning in Precalculus with E-learning Activities and Through Analyses of Student Learning Styles and Motivational Characteristics," American Society for Engineering Education Annual Conference \& Expo, Austin, TX AC 20091873 (2009).

10. D. Whalen, K. Saunders, M. Shelley, "Leveraging what we know to enhance short-term and long-term retention of university students,” J. College Student Retention, 2009-10,11(3) 407-430. 